\title{
Tecnologias: instrumentos de intervenção psicopedagógica em dificuldades de aprendizagem
}

\author{
Gessilda Cavalheiro Müller* e Silvana Corbellini** \\ * Escola Estadual de Ensino Fundamental Othelo Rosa - Rede Pública Estadual do Rio \\ Grande do Sul - 5132222492 - Av. Independência, 1065 - Porto Alegre - RS - Brasil \\ ** Departamento de Estudos Básicos - Faculdade de Educação - Universidade Federal \\ do Rio Grande do Sul (UFRGS) - 5133083424 - \\ Av. Paulo Gama, 110 - Porto Alegre - RS - Brasil \\ gessilda@gmail.com, silvanacorbellini@gmail.com
}

\begin{abstract}
Resumo. Este artigo mostra o desenvolvimento de uma pesquisa na área da Psicopedagogia e Tecnologias da Informação e da Comunicação - TICs. Em 2014 foi realizada uma intervenção psicopedagógica com um aluno do $4^{\circ}$ ano do ensino fundamental de uma escola pública de Porto Alegre-RS. O aluno apresentava dificuldades de aprendizagem na leitura e na escrita. Foi realizado um estudo de caso e ao longo do trabalho foi utilizada a tecnologia como instrumento principal para intervenção com o aluno. Os resultados da intervenção foram consistentes, o aluno apresentou avanços em relação à aprendizagem da leitura e da escrita. O uso das TICs foi fundamental para o avanço alcançado, pois despertou o interesse e a motivação do aluno para a aprendizagem.
\end{abstract}

Palavras-chaves. Aprendizagem; Intervenção; Psicopedagogia; Tecnologia.

\section{Introdução}

Este artigo mostra o desenvolvimento de uma pesquisa na área da Psicopedagogia e Tecnologias da Informação e da Comunicação - TICs. Em 2014 foi realizada uma intervenção psicopedagógica com um aluno do $4^{\circ}$ ano do ensino fundamental de uma escola pública de Porto Alegre-RS. O aluno apresentava dificuldades de leitura e escrita. Sendo assim, verificamos a necessidade da compreensão das relações entre 0 desenvolvimento cognitivo, dificuldades de aprendizagem na leitura e na escrita, e o uso das Tecnologias da Informação e da Comunicação para ampliar a aprendizagem.

O objetivo desta pesquisa era verificar qual o efeito de uma intervenção psicopedagógica realizada com um aluno do ensino fundamental com dificuldades na leitura e na escrita, utilizando as TICs como instrumento principal de intervenção. Em virtude disso, foi desenvolvido um estudo de caso de acordo com Yin (2005). A hipótese levantada para esta pesquisa foi verificar se o uso das TICs poderia ser um instrumento eficaz na intervenção psicopedagógica

Para fundamentação teórica desta pesquisa utilizamos diversos autores. Na área da Psicopedagogia nos reportamos a Scoz (2004) e Bossa (2007). Na área da leitura e escrita utilizamos as contribuições de Golbert e Moojen (1996) e Moojen e França 
(2016). E, por fim, para a fundamentação do uso das TICs buscamos as pesquisas de Scattone e Masini (2007) e Valente (1999).

A seguir apresentaremos, numa primeira parte, seções 2 a 4, uma breve revisão teórica referente à importância do trabalho psicopedagógico, às dificuldades de aprendizagem na leitura e na escrita, e ao uso das TICs como recurso de ensino e aprendizagem. Numa segunda parte, seções 5 a 7, faremos a apresentação do caso, entrevistas, desenvolvimento da intervenção psicopedagógica, resultados, discussões e conclusões.

\section{O trabalho psicopedagógico}

A Psicopedagogia surgiu a partir da necessidade de uma melhor compreensão dos processos de aprendizagem. É uma área que vem crescendo consideravelmente e está cada vez mais conquistando espaço no nível teórico, científico e profissional conforme apontam Scoz (2004) e Bossa (2007). Scoz (2004) ressalta que a Psicopedagogia é a área mais indicada para atender crianças com problemas de aprendizagem e Bossa (2007, p. 19-20) enfatiza a questão interdisciplinar. De acordo com a pesquisadora, a Psicopedagogia " $[. .$.$] tem procurado sistematizar um corpo teórico próprio, definir o seu$ objeto de estudo, delimitar o seu campo de atuação; para isso, recorre à psicologia, psicanálise, linguística, fonoaudiologia, medicina e pedagogia." Desta forma, o trabalho psicopedagógico poderá ajudar o aluno no momento em que ele se defrontar com as dificuldades de uma tarefa, com seus bloqueios, sentimentos de angústias, vínculos com as pessoas, e etc.

Fernández, citada por Oliva (2008) afirma que o meio ambiente pode interferir nos problemas de aprendizagem e faz uma distinção entre as palavras: intervir e interferir - inter-vir (vir "entre") e inter-ferir (ferir "entre). Esse esclarecimento é importante para entendermos que o meio ambiente sempre irá intervir, mas em alguns momentos poderá interferir de forma negativa na aprendizagem. A tarefa do psicopedagogo é intervir no processo de ensino e aprendizagem e não deixar que haja interferência (negativa) do meio ambiente.

\section{Dificuldades de aprendizagem na leitura e na escrita}

Corso (2008) ressalta que as dificuldades de aprendizagem não podem ser entendidas a partir de um único fator - professor, métodos, recursos, escola ou sistema - pois elas podem estar em vários fatores ao mesmo tempo. Moojen (1999) complementa dizendo que as dificuldades de aprendizagem significam o resultado de um baixo rendimento escolar em consequência de diversos fatores isolados, ou em interação, como: falta de interesse e motivação, perturbação emocional, inadequação metodológica ou mudança no padrão de exigência da escola.

Golbert e Moojen (1996) afirmam que muitas crianças apresentam dificuldades na aquisição e no domínio da relação grafema/fonema, na compreensão dos significados do texto escrito e na fluidez da leitura. Essas dificuldades podem estar relacionadas com duas etapas principais: aquisição e desenvolvimento. A primeira etapa pode estar relacionada com dificuldades ocorridas na alfabetização, ou seja, descoberta e generalização de letras e sons. A segunda etapa pode estar relacionada com uma "[...] ruptura no padrão qualitativo da leitura: o aluno perde a fluência, repete sílabas e palavras, vacila, comete falhas na decodificação, omitindo, acrescentando e/ou 
substituindo palavras" (Golbert e Moojen, 1996, p. 101). As pesquisadoras ressaltam ainda, que as dificuldades na leitura também podem ser resultados do uso de metodologias inadequadas e mecanicistas sobre as relações entre letra e sons e por esse motivo não despertam interesse da criança pela leitura.

Assim como a leitura, a aquisição da escrita também envolve habilidades complexas. Na escola são exigidos que os alunos produzam textos coerentes, criativos, gramaticalmente e ortograficamente corretos. No entanto, nem sempre as práticas escolares respeitam os erros naturais do processo de aprendizagem. Golbert e Moojen (1996, p. 102) ressaltam que com isso "[...] tiram do aluno o interesse pela comunicação escrita, assim como as práticas mecanicistas impedem que a criança descubra as verdadeiras funções e usos da língua escrita".

Moojen e França (2016) fazem uma distinção entre as dificuldades de aprendizagem e transtorno de aprendizagem. As dificuldades de aprendizagem são passageiras e podem estar relacionadas com uma metodologia de ensino inadequada, falta de assiduidade e problemas pessoais ou familiares temporários. Essas dificuldades tendem a regredir com maior esforço do aluno ou ajuda pedagógica. Já os transtornos são específicos de leitura, escrita ou matemática.

\section{TICs como recurso de ensino e aprendizagem}

Atualmente muitos estudantes usam com frequência o celular, o computador e a internet. Baixam músicas, filmes, jogos, usam redes sociais, ferramentas de bate papo, publicam vídeos, etc. sendo exemplos Facebook, Whatsapp, YouTube, Twitter. No entanto, a maior parte dos acessos são realizados fora da escola. Em muitas instituições de ensino esses recursos não são usados como instrumentos de ensino e aprendizagem. Valente (1999) ressalta a importância das TICs na educação como uma ferramenta de complementação, aperfeiçoamento e possível mudança na qualidade do ensino. O uso adequado das TICs possibilita a criação de condições para os estudantes exercitarem a capacidade de procurar e selecionar informações, resolver problemas e aprender de forma autônoma.

Scattone e Masini (2007) descrevem uma pesquisa realizada com alunos do $4^{\circ}$ ano do ensino fundamental sobre a importância do trabalho com softwares educativos para o enriquecimento do processo ensino e aprendizagem. Muitos alunos chegavam ao consultório de Psicopedagogia com queixas de dificuldades de aprendizagens escolares. No entanto, durante a intervenção psicopedagógica, quando solicitados a expor produções ou realizar tarefas, os alunos apresentavam uma resistência ao ato de aprender. Scattone e Masini (2007, p. 241) também verificaram que, enquanto os estudantes "se preocupavam em evitar o erro a disponibilidade para o processo ensinoaprendizagem ficava prejudicada." Os resultados da pesquisa apontaram que o recurso utilizado contribuiu para melhorar o interesse e a motivação dos alunos para a aprendizagem.

Como já ressaltado, muitos estudantes usam a tecnologia fora da escola, enquanto isso, os laboratórios escolares não são usados para qualificar a aprendizagem. Demo (2012, p. 14) aponta a falta de capacitação dos professores para trabalhar com os alunos nos laboratórios de informática da escola. Nevado (2004) ressalta a importância da formação de professores em ambientes virtuais de aprendizagem. Para a 
V Congresso Brasileiro de Informática na Educação (CBIE 2016)

Anais dos Workshops do V Congresso Brasileiro de Informática na Educação (CBIE 2016)

pesquisadora, o processo de formação continuada permite condições para que o professor construa conhecimento.

Tendo como referência esta fundamentação teórica, a seguir apresentaremos o método de pesquisa, o caso e o desenvolvimento da intervenção psicopedagógica. Por fim, serão apresentadas as conclusões.

\section{Método de pesquisa}

A seguir serão apresentadas as bases da construção metodológica, envolvendo tipo de pesquisa, problema, objetivo, hipótese e amostra. Na sequência, são descritos os procedimentos, os instrumentos de avaliação e atividades de intervenção.

Para realização deste trabalho foi utilizado o estudo de caso conforme Yin (2005) como estratégia de pesquisa e os dados foram analisados qualitativamente. Minayo (2007) destaca que a investigação qualitativa exige que o pesquisador tenha abertura, flexibilidade, capacidade de observação e de interação com os participantes.

O problema de pesquisa foi organizado da seguinte forma: Qual o efeito de uma prática psicopedagógica realizada com um aluno do $4^{\circ}$ ano do ensino fundamental com dificuldades na leitura e na escrita, utilizando as TICs como instrumento principal de intervenção?

O objetivo geral desta pesquisa: fazer uma análise dos efeitos de uma prática psicopedagógica com um aluno do $4^{\circ}$ ano do ensino fundamental com dificuldades na leitura e na escrita tendo como instrumento principal as TICs.

Hipótese do trabalho: verificar se o uso das TICs é um instrumento eficaz na intervenção psicopedagógica com um aluno com dificuldades na leitura e escrita.

Para que o aluno pudesse participar da pesquisa foi solicitada a autorização por escrito dos pais através do termo de consentimento livre e esclarecido.

Os procedimentos da coleta de dados foram divididos em três etapas distintas, ou seja, observações e entrevistas, prática psicopedagógica, resultados e discussão dos dados.

\subsection{Apresentação do caso}

O estudo de caso foi realizado com o menino $\operatorname{Ian}^{1}$ de nove anos de idade, estudante do $4^{\circ}$ ano do ensino fundamental de uma escola pública de Porto Alegre - RS. Ele é filho único de pais separados que possuem a guarda compartilhada.

De acordo com a mãe, Ian estudou em escola particular do $1^{\circ}$ ano até o $3^{\circ}$ ano do ensino fundamental e sempre ficou no turno integral. No entanto, a família estava passando por dificuldades financeiras e o filho seria transferido para uma escola pública. A mãe relatou que no final do ano de 2013 o filho tinha passado do $3^{\circ}$ para o $4^{\circ}$ ano, mas a professora tinha sugerido que ele estudasse durante as férias. A mãe relatou que não tinha observado que o filho estava com dificuldades em Português. A mãe disse que até tentou estudar com Ian, mas não deu certo em função de brigas e de sua falta de

\footnotetext{
${ }^{1}$ Ian é um nome fictício.
} 
paciência com o filho. Relatou também que ele era preguiçoso, não se interessava pelo estudo, era demorado para fazer temas e perdia os materiais. O pai de Ian concordava em parte com a mãe, mas ressaltou que o filho era atencioso, habilidoso, gostava de ouvir histórias, assistir filmes e brincar com jogos e que não via ele como preguiçoso.

\subsection{Observações e entrevistas}

Anamnese com os pais: A anamnese foi realizada na casa da mãe de Ian e o pai também estava presente. Para organização da entrevista foi utilizado como referência o texto de Rotta, Ohlweiler e Riesgo (2006) e de Weiss (1987). A mãe tinha 34 anos e trabalhava no comércio. O Pai tinha 38 anos e fazia serviços de tele-entrega. A mãe afirmou que teve Ian com 25 anos, a gestação foi tranquila e não apresentou problemas de saúde. Foi a primeira gestação, não foi planejada, mas foi aceita após confirmação. O parto foi cesária, pois não tinha dilatação necessária. Ian caminhou em torno de um ano e no mesmo período começou a falar palavras. O controle esfincteriano demorou a ser feito. Com relação ao grau de independência nas atividades da vida diária os pais relataram que ainda ajudam o filho a vestir-se, tomar banho, organizar os objetos pessoais e o quarto. O pai relatou que a mãe não é muito organizada e isso ajuda na desorganização do filho.

Entrevista com o aluno: O trabalho foi realizado ao longo do ano de 2014 na casa do menino, com dois encontros semanais. Inicialmente, o menino se mostrou um pouco assustado. Durante a entrevista, Ian disse que não sabia ler direito e isso o deixava angustiado e com muita vergonha na frente dos colegas. Por esse motivo, gostava mais de matemática ressaltando: eu sou bom em matemática e também gosto de jogos. Da primeira escola lembra somente dos amigos e que era muito quieto na sala. Na escola atual foi muito bem acolhido pela professora e colegas. Brinca no recreio, "fala" muito na sala de aula e a professora já chamava atenção. Comentou que não usava as TICs na escola e nem em casa, mas gostaria de aprender, pois tinha curiosidade de conhecer alguns "joguinhos" que os colegas jogam. Sabia que a mãe tinha Facebook e e-mail para conversar com os amigos e familiares. Não entendia como o uso das TICs poderia ajudar a melhorar a leitura e a escrita. Além disso, Ian comentou sobre a falta de paciência e das reclamações da mãe diante de suas dificuldades e como se sentia mal com isso. Também observei o quanto o menino era carente de carinho e atenção e sentia a falta da mãe, pois ela trabalhava o dia inteiro.

Entrevista com a professora: A professora relatou que a turma era composta por 24 alunos bem agitados e exigentes. Ian era um aluno muito querido que se adaptou muito bem na escola e na turma. No entanto, apresentava muitas dificuldades na leitura e na escrita. A letra era ilegível, não conseguia copiar do quadro, se distraía com facilidade, apresentava certa lentidão para copiar e resolver as tarefas. A professora já tinha chamado os pais e solicitado acompanhamento pedagógico fora da escola. Pois, caso contrário, ele não conseguiria acompanhar a turma. Ela não usava o laboratório de informática, pois a conexão era ruim, alguns computadores estavam estragados e ela não se sentia segura o suficiente para acompanhar os alunos, pois não tinha professora de informática. Usava muito o livro didático e o quadro. 
V Congresso Brasileiro de Informática na Educação (CBIE 2016)

Anais dos Workshops do V Congresso Brasileiro de Informática na Educação (CBIE 2016)

\subsection{Avaliação e prática psicopedagógica}

Após as entrevistas foi realizado contato com local de estudo de Ian e revisão dos materiais do ano anterior (cadernos e livros). Foi realizada Sessão lúdica diagnóstica tendo como base o texto de Weiss (1992). Foi possível observar a relação do menino com os diferentes e diversos materiais apresentados. Ian ficou encantado com a proposta, manuseou a maioria dos materiais apresentados, no entanto, separou para brincar todos os objetos que não tinham portadores de texto. Durante o período de avaliação foram feitas diversas atividades envolvendo leituras de livros com pequenos textos, discussões sobre a leitura, escrita de palavras e frases, jogos matemáticos, jogos de construção e encaixe, e desenhos. Além disso, foi necessário organizar espaço para estudo (organização de materiais, mesa, brinquedos, etc) e organização de um calendário com dias e horários das aulas. Os resultados das avaliações mostraram que as dificuldades de Ian estavam relacionadas à leitura, que não era fluente, e a escrita.

As intervenções foram organizadas a partir das dificuldades observadas no processo diagnóstico. Esclarecemos que o trabalho com Ian foi realizado durante todo o ano de 2014, mas para este artigo foram considerados os quatro encontros destinados à avaliação e mais às atividades estruturadas e desenvolvidas em 10 encontros de 50 minutos, uma vez por semana.

Dentre as várias noções e habilidades que mereciam atenção, foram priorizadas atividades como: leitura de textos simples e interpretação; escrita de palavras, frases e pequenos textos; trabalhos com o alfabeto; diversos tipos de jogos de tabuleiro e online. No quadro 1 será apresentada a descrição das sessões realizadas com Ian.

\section{Quadro 1 - roteiro das sessões}

\begin{tabular}{|c|l|}
\hline Sessões & \multicolumn{1}{|c|}{ Descrição das Sessões } \\
\hline $\mathbf{1}$ & $\begin{array}{l}\text { Desenho da família e escrita dos nomes de cada um. Realização de um } \\
\text { acróstico com o seu nome. Uso de letras móveis para escrita dos nomes das } \\
\text { pessoas da família e dos amigos. }\end{array}$ \\
\hline $\mathbf{2}$ & $\begin{array}{l}\text { Descrição da história do nome: o que significa, quem o escolheu, por quem foi } \\
\text { escolhido. Início da organização de uma história em quadrinhos contando a } \\
\text { história do nome. }\end{array}$ \\
\hline $\mathbf{3}$ & $\begin{array}{l}\text { Finalização da história em quadrinhos, uso do computador: jogos online } \\
\text { Cover Orange 2 e sopa de letrinhas (Escola Game) e desenhos no Paint. }\end{array}$ \\
\hline $\mathbf{4}$ & $\begin{array}{l}\text { Retomada das sessões anteriores. Jogo das Palavras (Clubinho - Faber Castel) } \\
\text { interpretação, escrita de palavras, frases e pequenos textos; atividades com o } \\
\text { alfabeto, uso do computador. }\end{array}$ \\
\hline $\mathbf{5}$ & $\begin{array}{l}\text { Atividades com alfabeto móvel e online, escrita de palavras com letras } \\
\text { móveis, desenhos, dominó de palavras e figuras. }\end{array}$ \\
\hline $\mathbf{6}$ & $\begin{array}{l}\text { Atividades com o livro: Diário de um Banana: faça você mesmo (JEFF } \\
\text { KINNEY). Leitura, interpretação oral e escrita, desenho livre e Jogo Cover } \\
\text { Orange 2. }\end{array}$ \\
\hline $\mathbf{7}$ & $\begin{array}{l}\text { Retomada das sessões anteriores. Jogos online: Cover Orange 2 e Ordenação } \\
\text { de frases da Turma da Mônica. }\end{array}$ \\
\hline & As sessões 8, 9 e 10 tiveram como objetivo leitura, escrita, uso de letra \\
\hline
\end{tabular}




\begin{tabular}{|c|l|}
\hline & maiúscula e minúscula e sinais de pontuação, jogos no computador. \\
\hline $\mathbf{8}$ & $\begin{array}{l}\text { Atividades com livros da coleção Lelé da Cuca da Editora Ática. Leitura, } \\
\text { interpretação oral e escrita e desenhos da história. }\end{array}$ \\
\hline $\mathbf{9}$ & $\begin{array}{l}\text { Jogo online: Minecraft, entendimento do jogo, busca autônoma de } \\
\text { informações, escrita sobre o jogo. }\end{array}$ \\
\hline $\mathbf{1 0}$ & Retomada das sessões anteriores. Jogo online: Minecraft e Cover Orange 2. \\
\hline
\end{tabular}

Após a apresentação do desenvolvimento do trabalho serão apresentados os resultados da intervenção psicopedagógica, discussão dos dados e conclusões finais do estudo de caso.

\section{Resultados e discussão dos dados}

Com o desenvolvimento da intervenção psicopedagógica observamos que Ian apresentava facilidades para entender as ordens dos exercícios, rapidez de raciocínio e fazia relações com outros conteúdos. Falava muito bem sobre filmes, desenhos animados, passeios, etc. Além disso, mantinha a atenção focada durante as atividades e se mostrava prestativo e interessado.

Como forma de organização e para observarmos a evolução de Ian, os resultados serão apresentados em três momentos: antes, durante e após a intervenção psicopedagógica.

a) Antes da intervenção: dificuldades na leitura e na identificação das letras, o traçado da letra cursiva era ruim e não entendia o que escrevia. A interpretação de textos e histórias matemáticas ficava prejudicada. Os cadernos eram desorganizados, perdia seus materiais com frequência e recebia bilhetes da professora. Os bilhetes deixavam a mãe furiosa e com isso havia muitas brigas em casa. Esse quadro ainda era agravado pela baixa autoestima, Ian ficava na frente da TV comendo guloseimas e isso fazia com que aumentasse de peso.

b) Durante a intervenção - 10 sessões: evoluções na leitura, identificação de palavras com mais facilidade, pois só se atrapalhava com palavras desconhecidas. Decidiu sozinho que iria trocar de letra, passou a escrever com letra bastão, pois assim poderia escrever mais rápido. Aprendeu a lidar com o computador e realizava com prazer as atividades, acessava a internet, lia pequenos textos e procurava informações sobre filmes que já tinha visto no cinema. Apresentava dificuldades para leituras das palavras e instruções dos jogos de mesa e online. Na escrita, algumas palavras ainda continuavam ilegíveis e ocorriam omissões de letras. Melhora na interpretação de textos e histórias matemáticas. Os cadernos estavam um pouco mais organizados, os bilhetes da professora já tinham diminuído.

c) Após a intervenção: Ian apresentava mais facilidade na leitura e na interpretação. Conseguiu evoluir bastante, mas ainda precisava melhorar a letra. Os cadernos estavam bem mais organizados, na maioria das vezes, conseguia copiar tudo do quadro, não recebeu mais bilhetes da professora. Passou a tirar boas notas nas provas. Deu continuidade às atividades no computador e passou a ver que o uso das Tics podia ajudar a melhorar a aprendizagem.

Como já ressaltado anteriormente, Corso (2008) e Moojen (1999) afirmam que as dificuldades de aprendizagem não podem ser entendidas a partir de um único fator, pois elas podem estar em vários fatores ao mesmo tempo. A partir do relato dos pais 
podemos pensar que um primeiro fator envolvido poderia ser a questão emocional pela falta que Ian sentia da mãe. Mesmo não gostando das brigas era o momento de ser olhado, de chamar atenção. Fernandez (1991) lembra que o corpo manifesta a história emocional do individuo. Essa história vai sendo construída a partir das relações iniciais que são estabelecidas entre a criança e os pais ou cuidadores durante o desenvolvimento.

Ian pertence à classe média baixa e possui materiais adequados para a escola, tem acesso a lugares de lazer e meios de comunicação. No entanto, faltava o cuidado e orientação dos pais em relação ao uso dos materiais, organização da casa e do quarto, das roupas, alimentação, etc. A mãe não tinha paciência para estudar, ler e brincar com o filho e isso era o que ele mais desejava. Aos poucos, foi possível fazer sugestões aos pais de Ian, como por exemplo, organização do local para estudo. Alem disso, como Ian estava acima do peso, aos poucos, passou a andar de bicicleta com o pai. A mãe conseguiu com que Ian fizesse tratamento com um nutricionista e toda a família se envolveu para melhorar a alimentação.

Em relação às dificuldades na leitura e na escrita, verificamos que com a intervenção psicopedagógica Ian apresentou evoluções. Passou a ler pequenos textos em livros e no computador, lia as instruções dos jogos online, gostava de escutar histórias, de criar histórias em quadrinhos, melhorou a grafia das letras. Essas dificuldades podem estar relacionadas com duas etapas principais: aquisição e desenvolvimento. Pode ser que Ian tenha tido dificuldades nas duas etapas e isso teve reflexo ao longo da escolaridade conforme apontam Golbert e Moojen (1996). Antes da intervenção o menino sempre recusava leituras, escritas, jogos envolvendo letras e palavras, mostravase tenso e mudava de assunto. Com o desenvolvimento da intervenção, Ian passou a relaxar durante os encontros e isso era visível no corpo e nas expressões faciais. Já conseguia realizar atividades de leitura e escrita, tanto no papel, quanto no computador, com prazer e entusiasmo.

Outro fator que poderia estar causando a dificuldade de leitura e escrita em Ian é a questão da metodologia conforme apontam Golbert e Moojen (1996). Observamos que no início da intervenção Ian não queria escrever, pois sabia que escrevia errado. Ficava muito magoado, pois a professora sempre riscava as palavras com grafia errada. Para ele era um esforço enorme conseguir copiar e ainda estava errado. Na escola Ian precisava fazer muitas cópias do quadro e inclusive em casa os temas eram cópias enormes e sem significado do livro didático. Isso causava um desgaste muito grande sem contar com desmotivação e as brigas da mãe.

Com a mudança de escola e o acompanhamento psicopedagógico, Ian foi aos poucos mostrando evoluções no processo de aprendizagem. Aos poucos, verificamos uma melhora na organização e hábitos familiares e isso refletiu diretamente na aprendizagem Ian. Na escola o menino ficou mais motivado e sempre queria refazer as provas, mesmo que não tivesse ficado em recuperação, pois queria tirar uma nota melhor. É possível que Ian apresentasse dificuldade de aprendizagem evolutiva. Esses dados estão de acordo com Moojen e França (2016).

$\mathrm{Na}$ entrevista com a professora verificamos que ela não utilizava as TICs como instrumento de ensino e aprendizagem. Isso vem ao encontro com o que Demo (2012) fala sobre a falta de capacitação de professores para trabalhar no laboratório de infomática. Por isso a necessidade de uma formação continuada em ambientes virtuais de aprendizagem criando condições para que o professor construa conhecimento conforme ressaltado por Nevado (2004). 
Também foi observado que a família de Ian só tinha um computador notebook e o menino não tinha o hábito de usar. No entanto, durante a intervenção pedagógica foram usados o computador e o acesso à internet. Como Ian tinha pouco conhecimento prévio em relação à funcionalidade do computador, antes de propor as atividades, foi necessário fazer uma exploração livre, como por exemplo, posição das letras no teclado, ligar e desligar, organização de uma pasta na área de trabalho para guardar atividades, como abrir um novo documento para escrita, acessar à internet para procurar jogos, etc. Após a finalização do estudo de caso a situação financeira da família melhorou e Ian ganhou de aniversário um tablet e um celular. Isso contribuiu para ampliar ainda mais a motivação para aprendizagem.

No início do uso do computador Ian não tinha coordenação motora, antecipação e rapidez, não conseguia ler as instruções dos jogos e isso o deixava angustiado e em vários momentos queria desistir diante das dificuldades. Ao poucos tais atitudes foram sendo modificadas com o desenvolvimento da intervenção com o uso das TCIs. Com o uso frequente das TCIs, Ian passou a ter mais paciência nos jogos. Se divertiu muito experenciando o jogo Cover Orange 2 e Minecraft. Aos poucos, foi melhorando na coordenação motora, antecipação e rapidez. Desenvolveu habilidade com o mouse e no jogo da laranjinha (Cover Orange 2) conseguia colocar os obstáculos no lugar certo antes de chegar a chuva mortal. Tinha paciência para utilizar várias tentativas até acertar.

Além disso, Ian já conseguia lidar bem com as atividades online que abordavam a leitura e a escrita. Os resultados desta pesquisa corroboram com os dados de Scattone e Masini (2007). O uso das TCIs durante a intervenção psicopedagógica contribuiu para melhorar o interesse e a motivação de Ian em relação à leitura e à escrita. Inclusive ele não se constrangia com os erros cometidos e no final da pesquisa já refazia sem ser solicitado.

\section{Conclusões}

Nesta pesquisa tínhamos como objetivo fazer uma análise dos efeitos de uma prática psicopedagógica com um aluno do $4^{\circ}$ ano do ensino fundamental com dificuldades na leitura e na escrita, tendo as Tics como instrumento principal.

O problema de pesquisa foi respondido e a hipótese confirmada. Os resultados da intervenção psicopedagógica foram positivos. Portanto, o uso das TCIs como instrumento de intervenção se mostrou eficaz.

Nossos resultados são consistentes e corroboram com pesquisas apresentadas na fundamentação téorica. No entanto, vão além, pois a maioria dos estudos não utiliza as TCIs como instrumento de ensino e aprendizagem. Isso nos mostra que crianças como Ian são capazes, quando os espaços e equipamentos são orientados e disponibilizados para o uso. Então, se as TCIs forem utilizadas de forma adequada torna possível a criação de condições para que os alunos exercitem a capacidade de procurar e selecionar informações, resolver problemas, ter autonomia, etc.

A partir dos resultados desta pesquisa e considerando as dificuldades enfrentadas por muitos alunos do ensino fundamental em relação à leitura e à escrita, torna-se necessário buscar uma melhor compreensão para tais dificuldades. Assim, o desenvolvimento de outros estudos de caso e até estudos de casos múltiplos utilizando as TCIS se faz necessário. A continuidade da pesquisa é fundamental para indicar como 
V Congresso Brasileiro de Informática na Educação (CBIE 2016)

Anais dos Workshops do V Congresso Brasileiro de Informática na Educação (CBIE 2016)

avançar nos processos de prevenção e de intervenção a fim de superar as dificuldades de aprendizagem na leitura e na escrita.

\section{Referências}

Bossa, N. A Psicopedagogia no Brasil: contribuições a partir da prática. Porto Alegre:

Artmed, 2007

Corso, L. V. A Busca de Relações entre Dificuldades na Leitura e na Matemática: um estudo com alunos da $3^{\mathrm{a}}$ a $5^{\mathrm{a}}$ série do ensino fundamental. Tese (Doutorado em Educação) - Programa de Pós-Graduação, Faculdade de Educação, Universidade Federal do Rio Grande do Sul, Porto Alegre, 2008.

Demo, P. Educação, Avaliação Qualitativa e Inovação - I / Pedro Demo. - Brasília: Instituto Nacional de Estudos e Pesquisas Educacionais Anísio Teixeira, 2012. 28 p.: il. - Série Documental. Textos para Discussão

Golbert, C; Moojen, S Dificuldades na aprendizagem escolar. In: O aluno problema, Sukiennik (org.), Porto Alegre, Mercado Aberto, 1996.

Jogos. Disponível: www.jogosjogos.com/jogar-jogo/Cover-Orange-2.html. Acesso: 2014.

Minayo, M. C. O desafio do conhecimento. São Paulo, Editora Hucitec, 2007.

Moojen, S.; França, M. Dislexia: visão fonoaudiológica e psicopedagógica. IN: ROTTA, N. T. et al. Transtornos da Aprendizagem: Abordagem neurobiológica e Multidisciplinar. Porto Alegre: Artmed. 2016.

Nevado, R. A. Novos possíveis na formação de professores. In Franco (org.) Informática na educação: estudos interdisciplinares. Porto Alegre: Editora UFRGS, 2004.

Rotta, N., Ohlweiler, L. e Riesgo, R. Semiologia neurope-diátrica. In: Rotta, N., Ohlweiler, L. e Riesgo, R. Transtornos da aprendizagem. Abordagem neurobiológica e multidisciplinar. Porto Alegre: Ar-tmed, 2006. P. 65-70.

Scattone, C. e Masini, E. F. S. O software educativo no processo de ensinoaprendizagem: um estudo de opinião de alunos de uma quarta série do ensino fundamental. Rev. psicopedag. [online]. 2007, vol.24, n.75, pp. 240-250. ISSN 01038486.

Scoz, B. Psicopedagogia e Realidade Escolar. Petrópolis, RJ: Vozes, 2004.

Valente, J. A. O computador na sociedade do conhecimento (org.) Campinas, SP:UNICAMP/NIED, 1999.

Weiss, M. L. L. Psicopedagogia Clínica, Uma visão Diagnóstica - Ed. Artes Médicas, Porto Alegre - 1992.

Yin, R. K. Estudo de caso: planejamento e métodos. $3^{\circ}$ Ed. Porto Alegre: Bookman, 2005. 